\title{
The role of dopamine in positive and negative prediction error utilization during incidental learning - insights from Positron Emission Tomography, Parkinson's disease and Huntington's disease
}

David Mathar ${ }^{1,2}$, Leonora Wilkinson ${ }^{3}$, Anna Holl ${ }^{4}$, Jane Neumann ${ }^{1,2}$, Lorenz Deserno ${ }^{1,5,6}$, Arno Villringer ${ }^{1,2,7,8}$, Marjan Jahanshahi, ${ }^{3,9}$, Annette Horstmann ${ }^{1,2}$

${ }^{1}$ Dept. Neurology, Max Planck Institute for Human Cognitive and Brain Sciences, Leipzig, Germany 2Leipzig University Medical Center, IFB Adiposity Diseases, Leipzig, Germany

${ }^{3}$ Behavioral Neurology Unit, National Institute of Neurological Disorders and Stroke, National Institutes of Health, Bethesda, MD, USA

${ }^{4}$ Department of Psychiatry, Medical University of Graz, 8036 Graz, Austria

${ }^{5}$ Department of Psychiatry and Psychotherapy, Campus Charité Mitte, Charité-Universitätsmedizin Berlin, Berlin, Germany

${ }^{6}$ Department of Neurology, Otto-von-Guericke University, Magdeburg, Germany

${ }^{7}$ Clinic of Cognitive Neurology, University Hospital Leipzig, Leipzig, Germany

8Mind \& Brain Institute, Berlin School of Mind and Brain, Humboldt-University, Berlin,

Germany

9Sobell Department of Motor Neuroscience \& Movement Disorders, UCL Institute of Neurology, London, England

Correspondence should be sent to:

*Annette Horstmann, horstmann@cbs.mpg.de,

David Mathar, mathar@cbs.mpg.de

\section{${ }^{*}$ Corresponding author}

E-mail: horstmann@cbs.mpg.de

Phone: +493419940 2258

Fax: +493419940 2221

Max Planck Institute for Human Cognitive and Brain Sciences, Stephanstraße 1a, 04275 Leipzig, Germany.

Keywords: Procedural stimulus-response learning, Computational modeling, Dopamine, PET, Parkinson's disease, Huntington's disease

\section{Abstract}

Incidental learning of appropriate stimulus-response associations is crucial for optimal functioning within our complex environment. Positive and negative prediction errors 
(PEs) serve as neural teaching signals within distinct ('direct'/'indirect') dopaminergic pathways to update associations and optimize subsequent behavior. Using a computational reinforcement-learning model, we assessed learning from positive and negative PEs on a probabilistic task (Weather Prediction Task, [WPT]) in three populations that allow different inferences on the role of dopamine (DA) signals: (1) Healthy volunteers that repeatedly underwent [11C]raclopride Positron Emission Tomography, allowing for assessment of striatal DA release during learning, (2) Parkinson's disease (PD) patients tested both on and off L-DOPA medication, (3) early Huntington's disease (HD) patients, a disease that is associated with hyper-activation of the 'direct' pathway. Our results show that learning from positive and negative feedback on the WPT is intimately linked to different aspects of dopaminergic transmission. In healthy individuals, the difference in [11C]raclopride binding potential (BP) as a measure for striatal DA release was linearly associated with the positive learning rate. Further, asymmetry between baseline DA tone in the left and right ventral striatum was negatively associated with learning from positive PEs. Female patients with early HD exhibited exaggerated learning rates from positive feedback. In contrast, dopaminergic tone predicted learning from negative feedback, as indicated by an inverted-u-shaped association observed with baseline [11C]raclopride BP in healthy controls and the difference between PD patients' learning rate on and off dopaminergic medication. Thus, the ability to learn from positive and negative feedback is a sensitive marker for the integrity of dopaminergic signal transmission in the 'direct' and 'indirect' dopaminergic pathways. The present data are interesting beyond clinical context in that imbalances of dopaminergic signaling have not only been observed for neurological and psychiatric conditions but also been proposed for obesity and adolescence. 


\section{Introduction}

Incidental stimulus-response learning heavily relies on striatal functioning (Poldrack et al., 2001; Jahanshahi et al., 2010). Within the striatum, dopamine (DA) transmission is known to play a key role in fostering learning via encoding the difference between expectations and outcomes of our actions (Montague et al., 1996; Schultz et al., 1997; Schultz, 2002). These prediction error signals (PEs) are utilized to update current beliefs and, importantly, to adapt subsequent behavior. Positive PEs are signaled via a transient increase in firing rate ('burst') and negative PEs are associated with a pause in tonic firing ('dip'). It has been proposed that DA mediates learning from positive as well as negative outcomes (Van Der Schaaf et al., 2014), but via two segregated ('direct' I 'indirect') pathways (Frank, 2005; Frank and O'Reilly, 2006; Frank et al., 2007b; Kravitz et al., 2010). Recently, direct experimental evidence has been provided for this model in healthy volunteers (Cox et al., 2015).

In the 'direct pathway', striatal D1 receptor expressing neurons predominantly send inhibitory projections directly to the output nucleus of the basal ganglia, the globus pallidus interna/substantia nigra pars reticulata (GPi/SNr). Postsynaptic D1 receptors are sensitive to bursts in DAergic transmission. Thus, correct stimulus-response associations are strengthened via D1-receptor related modulation of synaptic plasticity within the direct pathway subsequent to positive PEs. In the 'indirect pathway' (Gerfen et al., 1990; Surmeier et al., 2007), striatal neurons expressing D2-receptors predominantly send inhibitory projections first to the external segment of the globus pallidus. From there inhibitory projections reach the subthalamic nucleus (STN). The STN then sends excitatory projections back to the GPi/SNr. Postsynaptic D2 receptors are sensitive to detecting transient dips within the tonic DA signal (Goto and Grace, 2005; Day et al., 2006). Hence, wrong stimulus-response associations are weakened through D2 receptor activity in the indirect pathway subsequent to negative PEs (Klein et al., 2007; Jocham et al., 2009, 2014). Importantly, too low tonic DA may impair D2 receptor-related signaling, as the magnitude of extracellular tonic DA determines the background stimulation of DA receptors (Grace, 1991). In addition, too high tonic DA release may impede D2 receptor-related signaling, as high tonic DA levels can inhibit the phasic DA response via action on presynaptic D2 auto-receptors (Goto et al., 2007) or via hyperpolarization of DAergic neurons (Dyakonova et al., 2009). Thus, either too low or too high tonic DA levels may specifically impede the capability of detecting dips and, consequently, may alter learning from negative PEs in particular. Further, recent data indicate that the hemispheric asymmetry of DA signals is related to the propensity to learn from positive vs. negative PEs (Maril et al., 2013; Tomer et al., 2014; Aberg et al., 2015). A mechanistic explanation for this phenomenon is missing to date. 
Consequently, it is important to differentiate between learning from positive and negative feedback to identify the specific involvement of different DA pathways or aspects of DA transmission. Further, an investigation of different aspects of DA transmission based on behavior on the same behavioral task will be beneficial for interpretation of the results.

Here, we assessed learning in response to positive and negative PEs in three populations that allow different inferences on the role of DA in incidental stimulusresponse learning. Importantly, all participants completed the same probabilistic learning task, the Weather Prediction Task (WPT, Knowlton et al., 1994). To differentiate between learning from positive and negative PEs, we employed a computational reinforcement-learning model.

First, we explored the influence of DAergic signaling in a sample of healthy volunteers who repeatedly underwent $\left[{ }^{11} \mathrm{C}\right]$ raclopride Positron Emission Tomography while completing the WPT with and without corrective feedback. Specifically, we investigated the impact of DA release, tonic DA level, and the asymmetry of phasic responses between left and right striatum on learning from positive and negative feedback. We hypothesized that the strength of phasic striatal DA transmission during procedural learning is linearly related to the participants' capability of learning from positive PEs. Further, we predicted that tonic DA levels within the striatum are associated with the ability to learn from negative PEs in an inverted u-shaped manner. Finally, we expected that asymmetry between left and right striatal signaling is related to learning from positive PEs.

Second, we investigated the effect of L-Dopa medication on learning from negative PEs in a sample of patients with Parkinson's disease (PD) who were tested both on or off medication when completing the WPT. Evidence (e.g. Agid et al., 1993; Kish, Shannak, \& Hornykiewicz, 1988) suggests that in early PD dopamine depletion is mainly limited to dorsal striatum and the ventral striatum is relatively less affected. We expected patients on levodopa medication to be selectively impaired in learning from negative PEs compared to off medication due to an nonspecific increase in DAergic tone in the ventral striatum in the on state (Cools et al., 2006; Frank et al., 2007a).

Third, we investigated learning in a sample of early Huntington's disease (HD) patients, a disease that is associated with a hyper-activation of the 'direct' pathway. Thus, we hypothesized that these patients will be selectively impaired in successful learning from positive PEs. 


\section{Methods}

\subsection{General methods}

\subsubsection{WPT}

All three studies (PET, PD \& HD) involved the same stimulus-response learning task, a standard version of the Weather Prediction Task ([WPT], Knowlton et al., 1994; see Figure 1 in Wilkinson et al., 2014), with corrective feedback to ensure learning based on striatal DA transmission. In the PET study, participants also completed a control version of the WPT without corrective feedback. Further, the card patterns in the control task were not related to the outcome.

On each trial, participants were presented with a particular arrangement of cards comprising one, two or three of the four possible tarot cards. Participants were asked to decide whether the presented set of cards predicted sunshine or rain. There were 14 possible arrangements of cards, as the four card and no card patterns were not used. The four cards were assigned with a probability for predicting sunshine of $80 \%, 60 \%$, $40 \%$ and $20 \%$, respectively, and predicting rain otherwise. Prediction probabilities for the presented arrangements of cards were derived from the joint probability distribution of the individual cards they contained. (see Table 2 in Wilkinson et al., 2014).

After presentation of the stimuli during each trial, participants were asked to predict the weather on that trial, which required them to classify the card arrangement into one of the two possible outcomes (e.g. rainy / fine). Responses were made either via two response buttons (PET / PD study) or verbally to the experimenter (HD study). Following their response, feedback appeared on the screen depending on whether the response was correct (thumbs up) or incorrect (thumbs down). The feedback and the card arrangement both remained on the screen for a short period. After they disappeared a blank screen preceded the presentation of the next combination of cards. If participants failed to make a response, the card arrangement appeared on the screen for the same duration but no feedback was provided. For more details on the particular task designs used in the respective studies please see the original publications (Jahanshahi et al., 2010 [PD study]; Holl et al., 2012 [HD study]; Wilkinson et al., 2014 [PET study]).

\subsubsection{Computational model}

Performance on the WPT relies on updating of outcome predictions and related adaptation of subsequent response behavior. Thus, the task was previously used to 
assess PE-related learning (Rodriguez et al., 2006). As the aim of our study was to assess differential learning from positive and negative feedback, from a conceptual point of view, our computational model needs to fulfill two criteria: (1) The model incorporates two learning rates, separating learning from positive and negative feedback, and (2) the two learning rates need to be interpretable independently from other model parameters. Consequently, we used a slightly modified version of the classical Q-learning model (Frank et al., 2007b) with two separate learning rates that are fitted independently of the choice consistency parameter $\beta$ (see equation (1)). The latter ensures that the learning rates are statistically independent of the choice consistency parameter, which is not the case when fitting is performed simultaneously. In more detail, our reinforcement learning model consists of four input nodes $I_{i=1, \ldots, 4}$ with weighted connections to two output nodes (Q-values) $Q_{j=1,2}$ that represent the presence or absence of the four different cues and the two possible outcomes in the WPT, respectively. On each trial, activity of the output nodes is computed as $Q_{j}=$ $\sum_{i} q_{i j} I_{i}$, where $q_{i j}$ is the weight connecting input node $I_{i}$ and output node $Q_{j}$. Weights are initialized to 0 and updated in each trial by means of $q_{i j}(k+1)=q_{i j}(k)+$ $\alpha^{+/-} S_{j}\left(R_{j}-Q_{j}\right) I_{i}$ where $R_{j}$ encodes the correct output in this trial and $S_{j}$ represents the subject's response. The latter is included for allowing the model to simulate the behavior of the individual participant rather than optimal learning. To assess learning from positive and negative PEs separately, we fitted two independent learning rates $\alpha^{+/-}$for $R_{j}-Q_{j} \geq 0$ and $R_{j}-Q_{j}<0$, respectively. For each participant the individual learning rates $\alpha^{+/-}$were determined that minimized the sum of squared differences between the model's output and the participant's response: $\sum_{j k}\left(S_{j k}-Q_{j k}\right)^{2} \rightarrow \min$, with $j=1,2$ and $k$ being the number of trials. In a subsequent step, we modeled each participant's choices of a particular outcome to follow a softmax distribution:

$P\left(\right.$ choice $\left.=S_{j} \mid Q_{1}, Q_{2}\right)=\frac{\exp \left(\beta Q_{j}\right)}{\exp \left(\beta Q_{1}\right)+\exp \left(\beta Q_{2}\right)}$ with $j=1,2$

The choice consistency parameter $\beta$ was fitted to participants' choices by minimizing the negative log likelihood of the choice probabilities $P$

$L L=-\ln \left(\prod_{k} P_{k}\left(Q_{j}\right)\right)$,

while the two learning rates were held constant at the values optimized in the first step. Model fitting and estimation of all parameters was accomplished by nonlinear optimization.

In order to ensure that the modifications to a standard Q-learning model did not compromise adequate model fit, we compared the model described above with (1) a similar model with only one learning rate instead of two and (2) a Q-learning model with 
simultaneous fitting of all three free parameters. For quantitative model comparison, we performed random-effects Bayesian model comparison (Daunizeau et al., 2014) to estimate exceedance probabilities and expected model frequencies (Stephan et al., 2009). Additionally, we utilized the Bayesian information criterion $B I C=-2 * L L+k^{*} \ln (n)$ (Schwartz, 1978), where $L L$ is the log likelihood of the model's choice probabilities, $\mathrm{k}$ is the number of free parameters of the respective model and $n=200$ represents the number of trials. Based on $B I C$ we computed $\triangle B I C$ values that represent mean differences (per subject) between the respective model and the model with the lowest $\mathrm{BIC}$ value. We also computed pseudo- $\mathrm{r}^{2}$ values as defined in Daw et al. (2006) to test if our model fitted subjects' learning performance above chance level.

In addition to a quantitative model fit comparison, we assessed if the respective models resembled participants' learning performance in a meaningful way. Therefore, we computed linear regression models with participants' mean percent correct responses as dependent variable and fitted model parameters as independent regressors.

Details of the model comparison are presented in Table 1. Across all subjects, model frequencies and exceedance probabilities favor standard QL which was identified as the best fitting model in $46 \%$ of participants. However, BIC values are almost identical for the three models and $\triangle \mathrm{BIC}$ values of 1.76 and 0.32 do not provide any strong evidence against the two competing models. In addition, pseudo- $r^{2}$ values show that all three models fit similarly above chance level. Within all different study populations, the stepwise 2LR model provides the best or second best model fit, again with pseudo-r ${ }^{2}$ values showing that the model fitted subjects' performance above chance level. Importantly, the stepwise 2LR model explained significant variance in participants WPT performance in all three studies according to regression analyses. Thus, modifications in our new model yield meaningful and independently interpretable parameter estimates without compromising adequate model fit.

\subsubsection{Statistical analyses}

All behavioral results were computed with PASW-SPSS-Statistics 19.0 (IBM Corporation, Somers, NY, USA). A significance criterion of $\alpha=.05$ was used, unless otherwise specified. All significance levels reported are two-tailed.

2.2. Methods PET study (Wilkinson et al., 2014)

\subsubsection{Participants}


Seven ( 3 female) healthy volunteers in the age of $45-70(M=56.86, S D=8.7)$ were recruited. None of the participants had any neurological disorder or history of psychiatric illness, drug or alcohol abuse or were on any drug treatments that might influence performance. Participants were asked not to smoke or drink caffeinated drink for at least $12 \mathrm{~h}$ prior to the scan, although we did not control for their average daily consumption of caffeine or nicotine. Participants completed the Beck Depression Inventory (BDI-II) (Beck et al., 1961, 1996) to preclude signs of depression. The study was approved by the Research Ethics Committee of Hammersmith, Queen Charlotte's and Chelsea and Acton Hospitals Trust. Permission to administer radioactive substances was granted by the Administration of Radioactive Substances Advisory Committee of the UK. All participants gave written informed consent to take part in this study in accordance with the Declaration of Helsinki. For more details on selected participants, please see Wilkinson et al. (2014).

\subsubsection{WPT}

All participants completed 400 trials of the WPT in eight blocks of 50 trials each while having a $\left[{ }^{11} \mathrm{C}\right]$ raclopride PET scan. For more details, see Wilkinson et al. (2014). Notably, here we analyzed participants' task performance across the first four blocks of 200 trials to assess learning, as afterwards participants' performance reached a plateau.

\subsubsection{Control task}

As for the WPT, the control task comprised 400 trials (of which we analyzed the first 200) that were completed while participants had a $\left[{ }^{11} \mathrm{C}\right]$ raclopride PET scan. On each trial participants were presented with an arrangement of between one and three of four possible cards, these were in the same positions on the screen as the card arrangements that were used in the experimental conditions. However, here the patterns on the four cards were identical and were not related to any outcomes or followed by corrective feedback. The card arrangements remained on the screen for a fixed period of $7 \mathrm{~s}$ after which they disappeared and the next card arrangement appeared after $2 \mathrm{~s}$. Participants were required to press a response button with their right index finger to indicate they had seen the card arrangements.

\subsubsection{Scanning procedure}


All participants underwent $\left[{ }^{11} \mathrm{C}\right]$ raclopride PET twice within four weeks. On each scanning session the respective task started 5 min before injection of tracer and ended 5 min before completion of $\left[{ }^{11} \mathrm{C}\right]$ raclopride PET (total duration $60 \mathrm{~min}$ ). Half of the participants completed the WPT during the first $\left[{ }^{11} \mathrm{C}\right]$ raclopride PET session and the remainder did the control task first.

\subsubsection{PET scanning}

As stated in Wilkinson et al. (2014) PET was performed using an ECAT EXACT HR+ (CTI/Siemens 962, Knoxville, TN) tomograph with a total axial field of $15.5 \mathrm{~cm} .63$ transaxial image planes were displayed as $2.46 \mathrm{~mm}$ slices with a reconstructed axial resolution of $5.4 \mathrm{~mm}$ and a transaxial resolution of $5.6 \mathrm{~mm}$. A 10-min transmission scan was performed prior to injection of the tracer to correct for tissue attenuation of $511 \mathrm{keV}$ gamma radiation. Dynamic emission scans were acquired in three-dimensional mode. The mean injected doses of $\left[{ }^{11} \mathrm{C}\right]$ raclopride for each group is listed in Table Table 1 of Wilkinson et al. (2014). Scanning began at the start of tracer infusion generating 20 periods over $60 \mathrm{~min}$. A laptop was used to present the WPT or control task to the participants, and the tasks commenced 5 min before the injection of RAC. RAC was supplied by Hammersmith Imanet.

\subsubsection{Image analysis}

As stated in Wilkinson et al. (2014) parametric images of $\left[{ }^{11} \mathrm{C}\right]$ raclopride binding potential $\left(\mathrm{BP}_{\mathrm{ND}}\right)$ were generated using a basis function implementation of the simplified reference tissue model using cerebellar cortex to estimate non-specific tracer uptake (Gunn et al., 1997). An image of integrated $\left[{ }^{11} \mathrm{C}\right]$ raclopride signal from 0 to 60 min (an "ADD" or summed image) was also created for each participant. The ADD images were then spatially normalized to an in-house $\left[{ }^{11} \mathrm{C}\right]$ raclopride template in standard stereotaxic (MNI) space using statistical parametric mapping (SPM2) software (Wellcome Functional Imaging Laboratory, London). The transformation matrices were then applied to the corresponding $\left[{ }^{11} \mathrm{C}\right]$ raclopride parametric image. A standard region-of-interest (ROI) object map that outlined putamen, heads of caudate nucleus and ventral striatum was defined on the $\left[{ }^{11} \mathrm{C}\right]$ raclopride template with magnetic resonance imaging guidance. The ROI object map was then applied to the individual $\left[{ }^{11} \mathrm{C}\right]$ raclopride parametric images to sample $\left[{ }^{11} \mathrm{C}\right]$ raclopride $\mathrm{BP}_{\mathrm{ND}}$. The investigator analyzing the scans was blinded to the task associated with each scan. 


\subsection{Methods PD study (Jahanshahi et al., 2010)}

\subsubsection{Participants}

Eleven individuals with a diagnosis of idiopathic PD (8 male) aged between 53 and 73 $(M=63.5, S D=6.2)$ were included. Patients were recruited from the Movement Disorders Clinics at the National Hospital for Neurology and Neurosurgery. They met Parkinson's Disease Society Brain Bank diagnostic criteria for PD (Hughes et al., 1992). Disease duration ranged from 3 to 37 years $(M=13.2, S D=10.7)$. Despite the wide range of disease duration, the majority of patients was in the early stage of PD, with disease durations of less than 14 years. Two patients, however, had relatively long disease duration of 30 and 37 years. Without those two patients the average disease duration was 8.76 years. Importantly, the results reported below did not change when the two subjects were excluded from the analyses (or disease duration was included as a covariate). All patients were non-demented as demonstrated by scores $>26$ on the Mini-Mental State Examination (MMSE) (Folstein et al., 1975) and non-depressed according to scores < 18 on the Beck Depression Inventory (BDI) (Beck et al., 1961). The MMSE has been recommended as a screening tool for identifying cognitively impaired patients and, specifically, for characterizing PD associated dementia (e.g. Dubois et al., 2007). All patients were treated with levodopa (Sinemet, Madopar) and were responding well and stable on their medication doses. PD patients were matched with the controls for age, education, sex, verbal IQ and dementia based on MMSE scores. For further details regarding the patient sample please see Jahanshahi et al. (2010).

Further, thirteen healthy volunteers ( 5 male) aged between 44 and $69(M=60.0, S D=9.7)$ took part in the study. None of the controls had any neurological disorder, psychiatric illness, head injury, history of alcohol or drug abuse, or depression (BDI). For more details see Jahanshahi et al. (2010).

\subsubsection{Task procedure}

All participants performed 200 trials of the WPT separated into four blocks of 50 trials each (for more details see e.g. Jahanshahi et al., 2010) twice with different but parallel stimuli and outcomes (rainy/fine or cold/hot) presented on each occasion. Six of the PD patients were tested off medication first and the remainder was tested on medication first. PD patients completed the off and on medication conditions on 2 separate days, with a mean delay of 11.9 days $(S D=6.9)$ in between. Controls completed the two assessments on the same day, separated by a long lunch break.

2.4. Methods HD study (Holl et al., 2012) 


\subsubsection{Participants}

Eighteen individuals ( 9 male) with genetically proven HD (for genetic details, see Table 1 in Holl et al. (2012)) aged between 32 and $68(M=50.28, S D=10.2)$ took part. Patients were recruited from the HD clinic at the National Hospital for Neurology and Neurosurgery and from the HD clinic at the Department of Psychiatry at Graz Medical University. Patients were in the early stages of the disease, with an average score on the Unified Huntington's Disease Rating Scale Total Functional Capacity (UHDRS TFC, Shoulson and Fahn, 1979) of $11.61(S D=.3)$. The UHDRS motor score (Hungtington Study Group, 1996) was used for assessment of motor symptoms, patients presented with an average score of $20.39(S D=10.4)$. All patients were non-demented, as demonstrated by scores $>24$ on the MMSE. The MMSE has been recommended as a screening tool for identifying cognitively impaired patients (e.g. Dubois et al., 2007). In addition, the patients were screened for clinical depression on the BDI. One patient had a BDI score of 18 and one had a score of 24 (moderate depression), but neither met the criteria for clinical depression in a psychiatric interview.

Eighteen healthy volunteers (9 male) aged between 30 and $74(M=50.00, S D=13.3)$ took part in the study. Controls were recruited via an advertisement at a local adult education center in London and a participant recruitment website. Prior to participation in the study, controls were interviewed and screened for suitability. None of the controls had any neurological disorder, psychiatric illness, head injury, or history of alcohol or drug abuse. Further screening of the controls was achieved through completion of the MMSE and BDI, on which the controls had mean scores in the normal range.

For further information on the patients and controls sample, please see Holl et al. (2012).

Unfortunately, we had to exclude one healthy participant and one HD patient from modeling analyses, due to partial data loss.

\subsubsection{Task procedure}

All participants performed 150 feedback-based trials of the WPT separated in three blocks of 50 trials each (for more details see Holl et al., 2012).

\section{Results}

\subsection{Results PET in healthy volunteers}




\subsubsection{Striatal ${ }^{11} \mathrm{C}$-Raclopride binding}

Here, we only report on post-hoc comparisons of RAC BPND between the WPT and baseline task across ROls utilizing independent samples t-tests. For more details on analyses regarding RAC BPND data, we refer the reader to Wilkinson et al. (2014).

There was a trend for a reduction in RAC BPND in the right and left ventral striatum when performing the WPT compared to the control task $(13.4 \%$ reduction in the right, $t(6)=-2.01, p=.09,6.0 \%$ reduction in the left, $t(6)=-2.18, p=.07$ ), indicating release of synaptic DA during feedback-based stimulus-response learning. This comparison did not trend towards significance for any other region, left putamen $(t(6)=-1.15, p=.29)$, right putamen and right and left caudate (all ts $<1$ ). For subsequent analyses we use the mean baseline and \% change in RAC BPND of left and right ventral striatum (9.7\%).

\subsubsection{Behavioral data}

As mentioned previously, in the original paper (Wilkinson et al., 2014) WPT mean proportion of correct responses across 8 blocks of 50 trials was analyzed. Here, we only analyzed participants' WPT performance across the first four blocks, as we were interested in the initial learning phase of the task. For this purpose, we utilize a repeated-measures ANOVA model with within-subjects factor block (4 levels). In addition, to assess the time of emergence and progression of learning across blocks in this condition, mean proportion of correct responses per block was compared to chance $(50 \%)$ for all four blocks using one sample t-tests. Following Bonferroni corrections we adopted a significance threshold of $\alpha=0.0125$.

Although the repeated-measures ANOVA reported no significant differences between task-blocks $(F(3,6)=1.6, p=.23)$ on learning performance, there was a trend for a linear association $(F(1,6)=4.47, \quad p=.08)$, indicating that participants' WPT performance increased across the initial four task-blocks. In line, participants' proportion of correct responses was significantly better than chance from block three onwards: (b1: $t(6)=3.31 ; \mathrm{b} 2: t(6)=3.08 ; \mathrm{b} 3: t(6)=3.72, p<.01 ; \mathrm{b} 4: t(6)=3.77, p<.01)$.

\subsubsection{Modeling}

As learning the WPT was related to DA transmission within the ventral striatum only, we focus on ventral striatal RAC BPND in subsequent analyses. We utilized two separate regression models to test our hypotheses regarding the associations of learning from positive and negative PEs with averaged ventral striatal RAC BPND measures.

The first regression model included positive learning rate as dependent variable and baseline RAC BPND and \% change in RAC BP $P_{N D}$ as regressors to test for a positive 
linear association between positive learning rates and phasic DA transmission. The second model included negative learning rate as dependent variable and baseline RAC $\mathrm{BP}_{\mathrm{ND}}$ as well as RAC $\mathrm{BPND}^{2}$ as regressors to test for a quadratic (inverted u-shaped) association between height of negative learning rate and tonic DA levels in the ventral striatum. In addition, we computed a regression model with positive learning rate as the dependent variable and ventral striatal DAergic asymmetry as a regressor. Asymmetry was assessed by percent difference between left and right baseline RAC BPND. Finally, we tested a possible quadratic (inverted u-shaped) association between modeled choice consistency and tonic DA release with a model similar to the second one. All regression models included age as a covariate to control for age related effects in DA transmission.

In line with our first hypothesis, learning from positive PEs showed a significant negative linear association with the \% change in RAC BP ${ }_{N D}$ within ventral striatum for WPT compared to control task assessment $\left(R^{2}=.89, \beta=-.94, p=.001\right.$, Figure $\left.1 \mathrm{~A}\right)$, indicating a positive linear association of phasic DA release and learning from positive PEs. Further, modeled negative learning rates showed a significant negative quadratic relationship with the baseline RAC BP $\mathrm{ND}\left(R^{2}=.89, \beta=-.74, p=.005\right.$, Figure $\left.1 \mathrm{~B}\right)$ in ventral striatum. In addition, we observed a significant negative linear relationship between positive learning rate and asymmetry between left and right ventral striatal baseline RAC BP $\mathrm{ND}$ $\left(R^{2}=.81, \beta=-.9, p=.006\right.$, Figure $\left.1 \mathrm{C}\right)$. Choice consistency was negatively associated with baseline RAC BP $\left.\mathrm{ND}^{2}=.87, \beta=-.91, p=.006\right)$ in a quadratic model.

\subsection{Results $P D$}

\subsubsection{Behavioral data}

As reported (Jahanshahi et al., 2010) WPT performance (averaged over 200 trials) of healthy controls did not differ significantly across sessions (session 1 (2): .68 (.72), $t(12)=-.99, p=.34)$. Therefore, their data were collapsed across assessments to compare PD patients' overall learning performance on and off medication with the performance of healthy controls. When off medication, patients' performance was comparable to the controls' combined performance $(t(35)=-.92, p=.36)$ indicating that dopamine levels within ventral striatum were still in an optimal range for learning the WPT. In contrast, when PD patients were tested on medication, their overall performance was significantly worse than the controls' combined performance $(t(35)=-2.26, p=.03)$.

To assess the impact of levodopa on PD patients' performance an repeated-measures ANOVA was performed on mean proportion of correct responses with medication (on vs. off) as a within subjects variable and order of testing (on first vs. off first) as a 
between groups variable. This analysis revealed a significant main effect of medication $(F(1,9)=11.45, p=.01)$. A post-hoc paired sample T-test revealed that PD patients showed better WPT performance off (.67) than on (.63) medication $(t(10)=2.72, p=.02$, Figure $2 \mathrm{~A})$. There was no significant main effect of order $(F(1,9)=1.64, p=.23)$ or order $\mathrm{x}$ medication interaction $(F(1,9)=4.89, p=.06)$.

\subsubsection{Modeling}

To test our hypothesis that PD patients on medication are specifically impaired in learning from negative PEs we set up a repeated-measures ANOVA with withinsubjects variable medication (off / on). As gender is known to modulate PD onset and phenotype (Haaxma et al., 2007) Van den Eden et al., 2003) we included it as a covariate. As there was no effect of order in the behavioral data we did not include this variable. We observed a significant main effect of medication on participants' negative learning rates $(F(1,9)=7.57, p=.02$, Figure $2 \mathrm{~B})$. A similar model yielded no significant effect of medication on positive learning rates $(F(1,9)=.07, p=.79)$. There was no significant effect of medication on modeled response consistencies $(F(1,9)=.16, p=.23)$.

\subsection{Results HD}

\subsubsection{Behavioral data}

We utilized a repeated measures ANOVA with within-subjects variable block (1-3) and between-subjects variable group (patients / controls). As the sample size (18) was reasonably large and there is recent evidence of gender-related differences in HD phenotype (Zielonka et al., 2013), we also included gender into our model. The analysis revealed a significant effect of block $(F(2,64)=17.1, p<.001)$ indicating that, on average, participants learned the task. Learning performance in general was different for healthy controls compared with HD patients as revealed by a significant main effect of group $(F(1,32)=5.64, p=0.02)$. The between-subject interaction of group $x$ gender was significant $(F(1,32)=4.9, p=.03$, Figure $3 A)$, showing that learning performance in general was different between gender-specific subgroups. In line, the three-way interaction of block $x$ group $\times$ gender exhibited a trend for significance $(F(2,64)=2.87$, $p=.06$ ), indicating that learning was different between gender specific control and HD groups. All other interactions were non-significant.

In view of the significant gender $x$ group interaction, post-hoc independent samples ttests revealed that female HD patients showed lower over-all learning performance than 
female control participants $(\mathrm{HD}=.72$, control $=.61, t(16)=3.5, p=.003)$, whereas there was no difference for men ( $\mathrm{HD}=.7$, control=.7, $t(16)=.11, p=.92)$.

\subsubsection{Modeling}

We computed two separate ANOVAs for positive and negative learning rates as dependent variables with group and gender as between-subject factors. There was no significant main effect in either model, but the group $x$ gender interaction had a significant impact on participants' positive learning rates $(F(1,30)=5.15, p=.03$, Figure $3 \mathrm{~B})$, whereas there was no such effect on learning rates from negative $P E s$ $(F(1,30)=.15, p=.7)$. Post-hoc independent samples t-tests revealed that female HD patients showed elevated learning from positive PEs compared to controls $(t(15)=2.13$, $p=.05$ ). There was no difference between male patients and control participants $(t(15)=.98, p=.34)$. In addition, positive learning rates showed a positive linear association with assessed motor symptom severity across all HD patients $\left(R^{2}=.3, \beta=.55\right.$, $p=.02$, Figure $3 C$ ). Motor symptom severity did not differ significantly between male and female HD patients $(t(15)=0.24, p=.81)$.

There was no significant main effect of group (HD / controls, $F(1,30)=2.14, p=.15$ ) or a group $x$ gender interaction $(F(1,30)=2.78, p=.11)$ on participants' response consistencies between HD patients and healthy controls.

\section{Discussion}

\subsection{Summary}

For optimal functioning within our complex environment procedural learning of appropriate stimulus-response associations is crucial. Positive and negative PEs serve as neural teaching signals within distinct pathways to update these associations and optimize our subsequent behavior. Positive PEs are reflected in an increase in the phasic firing rate of dopaminergic neurons, whereas negative prediction errors are reflected in transient dips of the tonic dopamine signal (Schultz et al., 1997; Tobler et al., 2003). Here, we assessed stimulus-response learning from positive and negative PEs on the probabilistic WPT using computational modeling. We included data from healthy volunteers and from two samples of patients exhibiting specific alterations in predominantly one of the two segregated pathways. Consequently, the different patient populations should reveal disturbances mainly in either learning from positive or learning from negative PEs. 
Taken together, our computational modeling results indicate that learning from positive and negative feedback on the WPT is intimately linked to different aspects of dopaminergic transmission. Phasic dopaminergic responses are predictive of learning from positive feedback on the WPT. In healthy individuals, we observed a linear association between difference in $\left[{ }^{11} \mathrm{C}\right]$ raclopride binding potential as a measure for striatal DA release and positive learning rate on the WPT. Further, asymmetry between baseline DA tone in left and right ventral striatum is negatively associated with learning from positive PEs. Female patients with early progression of Huntington's disease, which is characterized by a hyper-activation of the direct pathway, exhibited exaggerated learning rates from positive feedback. In contrast, dopaminergic tone predicts learning from negative feedback on the WPT, as indicated by an inverted-ushaped association observed with baseline $\left[{ }^{11} \mathrm{C}\right]$ raclopride binding potential in healthy controls and the difference between PD patients on and off medication.

\subsection{Learning from negative prediction errors on the Weather Prediction Task}

Dopaminergic tone predicts learning from negative feedback on the WPT, as indicated by an inverted-u-shaped association observed with baseline RAC BP in healthy controls. This is in line with previous research showing that avoidance learning was associated in an inverted-u-shaped manner with D2 receptor availability (Cox et al., 2015). Importantly, because $\left[{ }^{11} \mathrm{C}\right]$-raclopride is competing with endogenous dopamine, D2 receptor availability as estimated by $\left[{ }^{11} \mathrm{C}\right]$-raclopride binding potential may depend on both, the occupancy of receptors by endogenous dopamine and D2 receptor density. Thus, baseline BP may in part be interpreted as reflecting dopaminergic tone. It has been shown that either too low or too high tonic dopamine levels impair behavior in different cognitive domains (Cools and D'Esposito, 2011; Floresco, 2013). Non-optimal dopamine levels seem to affect particularly the capability of detecting dips in tonic DAergic signaling and, consequently, may thus alter learning from negative PEs in particular. In healthy volunteers, depletion of dopamine precursors specifically improves avoidance learning, presumably via a better signal-to-noise ratio due to a reduction of DA tone in the indirect pathway, but leaves approach learning unaffected (Cox et al., 2015). Our results indicate that in PD patients, however, a drastic increase in the level of ventral striatal dopamine impairs learning from negative PEs. L-DOPA has previously been shown to specifically impair reversal learning (Cools et al., 2001) and disrupt activity in the nucleus accumbens in PD patients (Cools et al., 2007). Since dopaminergic tone is associated with the ability to learn from negative PEs in an inverted u-shaped manner, our results suggest that ventral striatal dopaminergic tone in PD patients off medication is still preserved at an optimal level. This is corroborated by comparable performance of PD patients off medication and healthy controls. Additional administration of L-DOPA then causes a suboptimal increase in DA levels in the ventral 
striatum, resulting in an impaired ability to detect dips in tonic DA. PD patients in our subject sample also received DA agonists besides L-DOPA (see Jahanshahi et al., 2010). Thus, withdrawal from both or even withdrawal from DA agonists alone might have caused the observed differences in PD patients off vs. on medication (Moustafa et al., 2012). However, our results on differences in PD patients' learning from negative PEs between on and off medication are consistent with earlier reports on the effects of dopaminergic medication on reinforcement learning in PD patients using different tasks

(Frank et al., 2004, 2007a; Bodi et al., 2009). In line, Cools et al. (2006) demonstrated a medication-induced deficit that was restricted to conditions with unexpected punishment and Moustafa et al. (2013) reported reduced learning from negative feedback in PD patients under dopaminergic medication compared to unmedicated patients. Additionally, Moustafa et al. observed enhanced learning from positive feedback under dopaminergic medication. Notably, they used a simpler probabilistic stimulus-response learning task with only single cue stimuli. Together, these results suggest that dopaminergic tone predicts the ability to learn from negative PEs on the WPT, both in healthy individuals and in PD patients on dopaminergic medication. Importantly, the specific effect depends on the initial level of DA: Because of the basic non-linear relationship between DA levels and performance, additional heightening or lowering levels of DA might cause suboptimal performance on the WPT.

\subsection{Learning from positive prediction errors on the Weather Prediction Task}

Learning from positive PEs depends linearly on the magnitude of phasic dopamine release in healthy volunteers. Importantly, dopaminergic tone seems to be a powerful modulator of phasic DA transmission, as learning from positive PEs was best explained when we took into account both, \% change in RAC BP as a measure of phasic dopamine release during learning and baseline RAC BP as an indicator of density and background stimulation of DA receptors. These results are in line with a previous report demonstrating the direct association between learning from positive feedback and signaling in the direct pathway in healthy volunteers (Cox et al., 2015). In their study, learning to approach options associated with a positive outcome in a probabilistic selection task was linearly associated with $\mathrm{D} 1$ receptor density in the striatum.

Further, we found the ability to learn from positive PEs to be negatively associated with the asymmetry between baseline DA tone in left and right ventral striatum in healthy volunteers. Our results are in line with previous findings. Gray (1981) postulated that individual differences in motivational behaviour are related to either a bias towards behavioural activation to approach incentives or behavioural inhibition to avoid punishment. Stronger approach motivation has been linked to greater left than right prefrontal activation according to EEG power (e.g. Sutton and Davidson, 1997), as well 
as PET and fMRI-related activation (Wager et al., 2003; Murphy et al., 2003). Presumably, this asymmetric activation is related to hemispheric asymmetry in dopaminergic transmission. Hemispheric asymmetry in DA has repeatedly been shown to be associated with approach and avoidance motivation and learning. In healthy volunteers, self-reported motivational bias between approach and avoidance was predicted by the asymmetry of frontal D2 binding (Tomer et al., 2014). Further, striatal and frontal asymmetries in D2 dopamine receptor binding predicted individual differences in learning from reward versus punishment (Tomer et al., 2014). PD patients with predominantly left hemispheric deficits were less willing to invest effort to maximize gain, indicating a selective impairment in approach motivation. In contrast, PD patients with a right hemispheric deficit exhibited impairments in avoidance motivation (Porat et al., 2014). Further, these patients were impaired in learning from positive vs. negative feedback, respectively (Maril et al., 2013). In contrast to Aberg et al. (Aberg et al., 2015), who reported a positive association between better learning from positive PEs and functional asymmetry in left and right ventral striatum, our data indicate a negative relationship. This seeming discrepancy can be explained by the indirect modulation of phasic responses by DA tone via inhibitory actions on the presynaptic cell (Goto et al., 2007; Dyakonova et al., 2009).

So what happens if the balance between the integrity of direct and indirect pathways is compromised? Female patients with early progression of Huntington's disease, which is characterized by a hyper-activation of the direct pathway, exhibited exaggerated learning rates from positive feedback in our study. In Huntington's disease (HD), a neurodegenerative, autosomal-dominant transmitted neurodegenerative disorder, cell death of striatal neurons already occurs in early and even pre-symptomatic stages of the disease. The progression of neuronal death in the striatum is gradual and proceeds from dorsal to ventral and from medial to lateral (Vonsattel et al., 1985; Aylward et al., 2004). In early stages of HD, cell death primarily affects GABAergic medium-sized spiny neurons within the indirect pathway. Furthermore, HD has been associated with a loss of pre-synaptic D2 auto-receptors, thus impairing the ability of tonic DA to regulate phasic responses (Cepeda et al., 2014). Reduced striatal D2 receptor availability has been reported even in asymptomatic HD patients and mutation carriers, suggesting that dopaminergic signaling is compromised early in HD (Weeks et al., 1996; van Oostrom et al., 2009). Taken together, this leads to a hyper-activation of the direct pathway already in very early stages of the disease. In line, HD patients in early stages of the disease have been shown to be generally impaired in procedural stimulus-response learning (Holl et al., 2012). Adding to this, our results indicate that in early HD, DA pathways are affected differentially in women and men and that impairments are selective for learning from positive PEs. While we predicted specificity for learning from positive PEs, the finding of a gender-specific effect in patients with early HD is novel. It has been proposed that a general gender difference in endogenous dopamine levels or 
other aspects of dopaminergic transmission (Pohjalainen et al., 1998; Kaasinen et al., 2001; Laakso et al., 2002) may account for gender differences in the vulnerability to neuropsychiatric disorders such as depression, schizophrenia or Parkinson's disease (Gillies et al., 2014). For Huntington's disease, however, penetrance and prevalence seems to be equal for both sexes. Interestingly, a large European study showed recently that women with $\mathrm{HD}$ exhibited more severe symptoms and a faster progression of the disease (Zielonka et al., 2013), and a large US study found that women have a longer duration of the disease (Foroud et al., 1999). Thus, there might be gender differences in the progression of the disease. Our results indicate a more severe impairment in learning from positive PEs in women with HD compared to men. This might be explained by an interaction of disease-specific effects with sex differences in dopaminergic transmission. Women have a higher presynaptic dopaminergic synthesis capacity (Laakso et al., 2002) and show a lower binding potential for $\left[{ }^{11} \mathrm{C}\right]$ raclopride, suggestive of a higher striatal dopamine concentration (Pohjalainen et al., 1998). Further, women have been shown to have higher D2-like receptor binding potentials than men in frontal cortex, temporal cortex, and thalamus (Kaasinen et al., 2001). Together, these might produce an additive effect on the hyper-activation of the direct pathway, and, in consequence, exaggerated learning from positive PEs especially in women with early HD. However, as positive learning rate was associated with motor symptom severity across all patients, the gender specific effect might alleviate during further progression of the disease. In line with our results, Palminteri and colleagues observed an asymmetry in favor of reward-based relative to punishment-based learning in patients with early compared to late HD and to controls (Palminteri et al., 2012). Specifically, the authors found a higher reward bias and a higher reinforcement magnitude for gains compared to losses. However, learning rates for gain and loss conditions were not different between HD groups or compared to controls in their study. Importantly, the task they used differed from the WPT in that participants had to learn to approach, i.e. select, rewarding options and to avoid, i.e. to not choose, punishing options in different conditions. Taken together, our results indicate that future work should pay special attention to sex differences in HD.

An imbalance between tonic and phasic DA signaling may lie at the heart of alterations in dopamine-based learning, as has been observed in attention deficit hyperactivity disorder (Badgaiyan et al., 2015), depression (Dunlop BW and Nemeroff CB, 2007; Mörkl et al., 2016), schizophrenia (Juckel et al., 2006; Brunelin et al., 2013), obesity (Frank et al., 2012; Horstmann et al., 2015) or Parkinson's disease (PD) patients on dopaminergic medication (Jahanshahi et al., 2010). Further, within healthy volunteers, the layout of the dopaminergic system seems to be intimately linked to the individual level of personality traits such as approach/avoidance bias and impulsivity (Buckholtz et al., 2010; Tomer et al., 2014). 
Taken together, our results demonstrate that solving the WPT relies on the integrity of different pathways within the dopaminergic system. In line with our hypotheses, data from healthy individuals, patients with PD on dopaminergic medication as well as from patients with HD show that variance within each pathway is linked to specific performance differences when solving the WPT.

\section{Conclusions}

The present data reveal that the WPT is suitable to disentangle learning from negative and positive feedback with the help of computational modeling. The ability to learn from positive and negative feedback might prove to be a sensitive marker for the integrity of dopaminergic signal transmission. In particular, it might differentiate between the involvement of the 'direct' and 'indirect' dopaminergic pathways. The present data are interesting beyond clinical context in that imbalances of dopaminergic signaling have not only been observed for psychiatric conditions but also for obesity (Kessler et al., 2014; Horstmann et al., 2015) and adolescence (Luciana et al., 2012). Thus, future work should differentiate between learning from positive and negative feedback since these processes rely on segregate neural mechanisms. In the case of medical conditions, specific learning impairments would point to associated specific neural changes that call for different treatment options.

\section{Author contributions \& Funding}

DM and Annette Horstmann designed research, MJ, LW and Anna Holl contributed data, DM and JN implemented computational model, DM analyzed data, LD contributed to model comparisons, DM and Annette Horstmann wrote paper. All authors revised and edited the manuscript.

This work was supported by grants from the Federal Ministry of Education and Research (BMBF), Germany (to Annette Horstmann, JN, AV; FKZ: 01EO1001), the German Research Foundation (to Annette Horstmann, JN, AV; DFG-SFB1052), and stipends from the FAZIT-STIFTUNG (to DM; FAZIT-STIFTUNG Gemeinnützige Verlagsgesellschaft $\mathrm{mbH}$ ), and the Free State of Saxony (to DM; Landesstipendium). 


\section{References}

Aberg KC, Doell KC, Schwartz S (2015) Hemispheric Asymmetries in Striatal Reward Responses Relate to Approach - Avoidance Learning and Encoding of Positive Negative Prediction Errors in Dopaminergic Midbrain Regions. J. Neurosci. 35:1449114500

Agid Y, Ruberg M, Javoy-Agid F, Hirsch E, Raisman-Vozari R, Vyas S, Faucheux B, Michel P, Kastner A, Blanchard V (1993) Are dopaminergic neurons selectively vulnerable to Parkinson's disease? Adv. Neurol. 60:148-64 Available at: http://cat.inist.fr/?aModele=afficheN\&cpsidt=4120205 [Accessed July 25, 2016].

Aylward EH, Sparks BF, Field KM, Yallapragada V, Shpritz BD, Rosenblatt A, Brandt J, Gourley LM, Liang K, Zhou H, Margolis RL, Ross CA (2004) Onset and rate of striatal atrophy in preclinical Huntington disease. Neurology 63:66-72 Available at: http://www.ncbi.nlm.nih.gov/pubmed/15249612 [Accessed March 2, 2016].

Badgaiyan RD, Sinha S, Sajjad M, Wack DS (2015) Attenuated tonic and enhanced phasic release of dopamine in attention deficit hyperactivity disorder. PLoS One 10:114

Beck AT, Steer RA, Brown G (1996) Manual for the beck depression inventory (BDI-II). TX: Psychological Corporation.

Beck AT, Ward CH, Mendelson M, Mock J, Erbaugh J (1961) An inventory for measuring depression. Arch. Gen. Psychiatry 4:561-71 Available at: http://www.ncbi.nlm.nih.gov/pubmed/13688369 [Accessed January 10, 2013].

Bodi N, Keri S, Nagy H, Moustafa A, Myers CE, Daw N, Dibo G, Takats A, Bereczki D, Gluck MA (2009) Reward-learning and the novelty-seeking personality: A between-and within-subjects study of the effects of dopamine agonists on young parkinsons patients. Brain 132:2385-2395

Brunelin J, Fecteau S, Suaud-Chagny M-F (2013) Abnormal striatal dopamine transmission in schizophrenia. Curr. Med. Chem. 20:397-404 Available at:

http://www.pubmedcentral. nih.gov/articlerender.fcgi?artid=3866953\&tool=pmcentrez\&re ndertype=abstract [Accessed January 21, 2015].

Buckholtz JW, Treadway MT, Cowan RL, Neil D, Li R, Ansari MS, Baldwin RM, Schwartzman AN, Shelby S, Smith CE, Kessler RM, Zald DH (2010) Dopaminergic Network Differences in Human Impulsivity. 329:11-14

Cepeda C, Murphy KPS, Parent M, Levine MS (2014) The Role of Dopamine in Huntington 's Disease. Prog. Brain Res. 211:235-254

Cools R, Altamirano L, D'Esposito M (2006) Reversal learning in Parkinson's disease depends on medication status and outcome valence. Neuropsychologia 44:1663-1673

Cools R, Barker RA, Sahakian BJ, Robbins TW (2001) Enhanced or impaired cognitive function in Parkinson's disease as a function of dopaminergic medication and task 
demands. Cereb. Cortex 11:1136-1143

Cools R, D'Esposito M (2011) Inverted-U-shaped dopamine actions on human working memory and cognitive control. Biol. Psychiatry 69:e113-25

Cools R, Lewis SJG, Clark L, Barker RA, Robbins TW (2007) L-DOPA disrupts activity in the nucleus accumbens during reversal learning in Parkinson's disease.

Neuropsychopharmacology 32:180-189

Cox SML, Frank MJ, Larcher K, Fellows LK, Clark C a, Leyton M, Dagher A (2015) Striatal D1 and D2 signaling differentially predict learning from positive and negative outcomes. Neuroimage 109:95-101 Available at: http://dx.doi.org/10.1016/j.neuroimage.2014.12.070.

Daunizeau J, Adam V, Rigoux L (2014) VBA: A Probabilistic Treatment of Nonlinear Models for Neurobiological and Behavioural Data A. Prlic, ed. PLoS Comput. Biol. 10:e1003441 Available at: http://dx.plos.org/10.1371/journal.pcbi.1003441.

Daw ND, Doherty JPO, Dayan P, Seymour B, Dolan RJ (2006) Cortical substrates for exploratory decisions in humans. Nature 441:876-879

Day M, Wang Z, Ding J, An X, Ingham CA, Shering AF, Wokosin D, Ilijic E, Sun Z, Sampson AR, Mugnaini E, Deutch AY, Sesack SR, Arbuthnott GW, Surmeier DJ (2006) Selective elimination of glutamatergic synapses on striatopallidal neurons in Parkinson disease models. Nat. Neurosci. 9:251-259 Available at:

http://www.nature.com/doifinder/10.1038/nn1632 [Accessed April 13, 2016].

Dubois B et al. (2007) Diagnostic procedures for Parkinson's disease dementia: Recommendations from the movement disorder society task force. Mov. Disord. 22:2314-2324 Available at: http://doi.wiley.com/10.1002/mds.21844 [Accessed July 25, 2016].

Dunlop BW, Nemeroff CB (2007) THe role of dopamine in the pathophysiology of depression. Arch. Gen. Psychiatry 64:327-337 Available at:

http://dx.doi.org/10.1001/archpsyc.64.3.327\nhttp://archpsyc.jamanetwork.com/data/Jou rnals/PSYCH/11839/yrv60000_327_337.pdf.

Dyakonova VE, Chistopolsky I a., Dyakonova TL, Vorontsov DD, Sakharov D a. (2009) Direct and decarboxylation-dependent effects of neurotransmitter precursors on firing of isolated monoaminergic neurons. J. Comp. Physiol. A Neuroethol. Sensory, Neural, Behav. Physiol. 195:515-527

Floresco SB (2013) Prefrontal dopamine and behavioral flexibility: shifting from an "inverted-U" toward a family of functions. Front. Neurosci. 7:62 Available at: http://www.pubmedcentral. .nih.gov/articlerender.fcgi?artid=3630325\&tool=pmcentrez\&re ndertype=abstract [Accessed October 28, 2013].

Folstein M, Folstein S, McHugh P (1975) "Mini-mental state": a practical method for grading the cognitive state of patients for the clinician. J. Psychiatr. Res. 12:189-198 
Available at:

/citations?view_op=view_citation\&continue=/scholar\%3Fq\%3Dfolstein\%2Bfolstein\%2B mchugh\%26hl\%3Dde\%26as_sdt\%3D0,5\%26scilib\%3D1\&citilm=1\&citation_for_view=k GQy6cYAAAAJ:7uOkfv6XYJ4C\&hl=de\&oi=p [Accessed April 13, 2016].

Foroud T, Gray J, Ivashina J, Conneally PM (1999) Differences in duration of Huntington's disease based on age at onset. J. Neurol. Neurosurg. Psychiatry 66:52-6 Available at:

http://www.pubmedcentral.nih.gov/articlerender.fcgi?artid=1736160\&tool=pmcentrez\&re ndertype $=$ abstract.

Frank GKW, Reynolds JR, Shott ME, Jappe L, Yang TT, Tregellas JR, O'Reilly RC (2012) Anorexia nervosa and obesity are associated with opposite brain reward response. Neuropsychopharmacology 37:2031-46 Available at:

http://www.pubmedcentral.nih.gov/articlerender.fcgi?artid=3398719\&tool=pmcentrez\&re ndertype =abstract [Accessed December 19, 2013] .

Frank MJ (2005) Dynamic dopamine modulation in the basal ganglia: a neurocomputational account of cognitive deficits in medicated and nonmedicated Parkinsonism. J. Cogn. Neurosci. 17:51-72 Available at:

http://www.ncbi.nlm.nih.gov/pubmed/15701239.

Frank MJ, O'Reilly RC (2006) A mechanistic account of striatal dopamine function in human cognition: psychopharmacological studies with cabergoline and haloperidol. Behav. Neurosci. 120:497-517

Frank MJ, Samanta J, Moustafa AA, Sherman SJ (2007)(a) Hold Your Horses: Impulsivity, Deep Brain Stimulation, and Medication in Parkinsonism. Science (80-. ). 318:1309-1312 Available at: http://www.ncbi.nlm.nih.gov/pubmed/17962524.

Frank MJ, Scheres A, Sherman SJ (2007)(b) Understanding decision-making deficits in neurological conditions: insights from models of natural action selection. Philos. Trans. R. Soc. Lond. B. Biol. Sci. 362:1641-54 Available at: http://rstb.royalsocietypublishing.org/content/362/1485/1641.short.

Frank MJ, Seeberger LC, O'Reilly RC (2004) By carrot or by stick: cognitive reinforcement learning in parkinsonism. Science 306:1940-3 Available at: http://www.ncbi.nlm.nih.gov/pubmed/15528409.

Gerfen CR, Engber TM, Mahan LC, Susel ZVI, Chase TN, Monsma FJ, Sibley DR (1990) D1 and D2 Dopamine Receptor-Regulated Gene Expression of Striatonigral and Striatopallidal Neurons dopamine. :1429-1432

Gillies GE, Virdee K, McArthur S, Dalley JW (2014) Sex-dependent diversity in ventral tegmental dopaminergic neurons and developmental programing: A molecular, cellular and behavioral analysis. Neuroscience 282:69-85 Available at:

http://dx.doi.org/10.1016/j.neuroscience.2014.05.033.

Goto Y, Grace AA (2005) Dopaminergic modulation of limbic and cortical drive of 
nucleus accumbens in goal-directed behavior. 8:805-812

Goto Y, Otani S, Grace AA (2007) The Yin and Yang of dopamine release: a new perspective. Neuropharmacology 53:583-7 Available at:

http://www.pubmedcentral.nih.gov/articlerender.fcgi?artid=2078202\&tool=pmcentrez\&re ndertype=abstract [Accessed December 22, 2014].

Grace AA (1991) Phasic versus tonic dopamine release and the modulation of dopamine system responsivity: A hypothesis for the etiology of schizophrenia. Neuroscience 41:1-24

Gray J (1981) A Critique of Eysenck's theory of Personality In H. Eysenck, ed. A Model for Personality Springer Berlin / Heidelberg, p. 246-276.

Gunn RN, Lammertsma AA, Hume SP, Cunningham VJ (1997) Parametric imaging of ligand-receptor binding in PET using a simplified reference region model. Neuroimage 6:279-287 Available at: http://www.ncbi.nlm.nih.gov/pubmed/9417971.

Haaxma CA, Bloem BR, Borm GF, Oyen WJG, Leenders KL, Eshuis S, Booij J, Dluzen DE, Horstink MWIM (2007) Gender differences in Parkinson's disease. J. Neurol.

Neurosurg. Psychiatry 78:819-24

Holl AK, Wilkinson L, Tabrizi SJ, Painold A, Jahanshahi M (2012) Probabilistic classification learning with corrective feedback is selectively impaired in early Huntington's disease--evidence for the role of the striatum in learning with feedback. Neuropsychologia 50:2176-86 Available at:

http://www.ncbi.nlm.nih.gov/pubmed/22659110 [Accessed November 27, 2012].

Horstmann A, Fenske WK, Hankir MK (2015) Argument for a non-linear relationship between severity of human obesity and dopaminergic tone. Obes. Rev. 16:821-830 Available at: http://doi.wiley.com/10.1111/obr.12303.

Hughes A, Daniel S, Kilford L, Lees A (1992) Accuracy of clinical diagnosis of idiopathic Parkinson's disease: a clinico-pathological study of 100 cases. J. Neurol. Neurosurg. Psychiatry 55:181-184

Hungtington Study Group (1996) Unified Huntington's disease rating scale: reliability and consistency. Mov. Disord. 11:136-142

Jahanshahi M, Wilkinson L, Gahir H, Dharmaindra A, Dharmarinda A, Dharminda A, Lagnado DA (2010) Medication impairs probabilistic classification learning in Parkinson's disease. Neuropsychologia 48:1096-103 Available at: http://www.ncbi.nlm.nih.gov/pubmed/20006629 [Accessed November 27, 2012].

Jocham G, Klein T a, Neumann J, Cramon DY von, Reuter M, Ullsperger M (2009) Dopamine DRD2 polymorphism alters reversal learning and associated neural activity. J. Neurosci. 29:3695-704 Available at: http://www.pubmedcentral.nih.gov/articlerender.fcgi?artid=2694507\&tool=pmcentrez\&re ndertype=abstract [Accessed July 26, 2011]. 
Jocham G, Klein TA, Ullsperger M (2014) Differential Modulation of Reinforcement Learning by D2 Dopamine and NMDA Glutamate Receptor Antagonism. J. Neurosci. 34:13151-13162 Available at:

http://www.jneurosci.org/cgi/doi/10.1523/JNEUROSCI.0757-14.2014.

Juckel G, Schlagenhauf F, Koslowski M, Wuestenberg T, Villringer A, Knutson B, Wrase $J$, Heinz A (2006) Dysfunction of ventral striatal reward prediction in schizophrenia. Neuroimage 29:409-416

Kaasinen V, Någren K, Hietala J, Farde L, Rinne JO (2001) Sex differences extrastriatal dopamine D2-like receptors in the human brain. Am. J. Psychiatry 158:308-311

Kessler RM, Zald DH, Ansari MS, Cowan RL (2014) Changes in Dopamine Release and Dopamine D2 / 3 Receptor Levels with the Development of Mild Obesity. Synapse Available at: http://onlinelibrary.wiley.com/doi/10.1002/syn.21738/full [Accessed November 18, 2014].

Kish SJ, Shannak K, Hornykiewicz O (1988) Uneven Pattern of Dopamine Loss in the Striatum of Patients with Idiopathic Parkinson's Disease. N. Engl. J. Med. 318:876-880 Available at: http://www.nejm.org/doi/abs/10.1056/NEJM198804073181402 [Accessed July 25, 2016].

Klein T a, Neumann J, Reuter M, Hennig J, Cramon DY von, Ullsperger M (2007) Genetically determined differences in learning from errors. Science 318:1642-5 Available at: http://www.ncbi.nlm.nih.gov/pubmed/18063800 [Accessed March 14, 2012].

Knowlton BJ, Squire LR, Gluck MA (1994) Probabilistic Classification Learning in Amnesia. Learn. Mem. 1:106-120

Kravitz A V., Freeze BS, Parker PRL, Kay K, Thwin MT, Deisseroth K, Kreitzer AC (2010) Regulation of parkinsonian motor behaviours by optogenetic control of basal ganglia circuitry. Nature 466:622-626 Available at:

http://dx.doi.org/10.1038/nature09159.

Laakso A, Vilkman H, Bergman J, Haaparanta M, Solin O, Syvälahti E, Salokangas RKR, Hietala J (2002) Sex differences in striatal presynaptic dopamine synthesis capacity in healthy subjects. Biol. Psychiatry 52:759-63 Available at: http://www.ncbi.nlm.nih.gov/pubmed/12372667.

Luciana M, Wahlstrom D, Porter JN, Collins PF (2012) Dopaminergic modulation of incentive motivation in adolescence: age-related changes in signaling, individual differences, and implications for the development of self-regulation. Dev. Psychol. 48:844-61 Available at:

http://www.pubmedcentral.nih.gov/articlerender.fcgi?artid=3341492\&tool=pmcentrez\&re ndertype =abstract [Accessed January 16, 2015].

Maril S, Hassin-Baer S, Cohen OS, Tomer R (2013) Effects of asymmetric dopamine depletion on sensitivity to rewarding and aversive stimuli in Parkinson's disease. 
Neuropsychologia 51:818-824 Available at:

http://dx.doi.org/10.1016/j.neuropsychologia.2013.02.003.

Montague PR, Dayan P, Sejnowski TJ (1996) A framework for mesencephalic dopamine systems based on predictive Hebbian learning. J. Neurosci. 16:1936-47 Available at: http://www.ncbi.nlm.nih.gov/pubmed/8774460.

Mörkl S, Blesl C, Jahanshahi M, Painold A, Holl AK (2016) Impaired probabilistic classification learning with feedback in patients with major depression. Neurobiol. Learn. Mem. 127:48-55

Moustafa A a, Krishna R, Eissa AM, Hewedi DH (2013) Factors underlying probabilistic and deterministic stimulus-response learning performance in medicated and unmedicated patients with Parkinson's disease. Neuropsychology 27:498-510 Available at: http://www.ncbi.nlm.nih.gov/pubmed/23876122.

Moustafa AA, Herzallah MM, Gluck MA (2012) Dissociating the Cognitive Effects of Levodopa vs . Dopamine Agonists in a Neurocomputational Model of Learning in Parkinson's Disease. :1-21

Murphy FC, Nimmo-Smith I, Lawrence AD (2003) Functional neuroanatomy of emotions: a meta-analysis. Cogn. Affect. Behav. Neurosci. 3:207-33 Available at: http://www.ncbi.nlm.nih.gov/pubmed/14672157 [Accessed August 5, 2016].

Oostrom JCH van, Dekker M, Willemsen a TM, Jong BM de, Roos R a C, Leenders KL (2009) Changes in striatal dopamine D2 receptor binding in pre-clinical Huntington's disease. Eur. J. Neurol. 16:226-31 Available at: http://www.ncbi.nlm.nih.gov/pubmed/19138335.

Palminteri S, Justo D, Jauffret C, Pavlicek B, Dauta A, Delmaire C, Czernecki V, Karachi C, Capelle L, Durr A, Pessiglione M (2012) Critical Roles for Anterior Insula and Dorsal Striatum in Punishment-Based Avoidance Learning. Neuron 76:998-1009

Pohjalainen T, Rinne JO, Någren K, Syvälahti E, Hietala J (1998) Sex differences in the striatal dopamine D2 receptor binding characteristics in vivo. Am. J. Psychiatry 155:768-773

Poldrack R a, Clark J, Paré-Blagoev EJ, Shohamy D, Creso Moyano J, Myers C, Gluck $\mathrm{M}$ a (2001) Interactive memory systems in the human brain. Nature 414:546-50 Available at: http://www.ncbi.nlm.nih.gov/pubmed/11734855.

Porat O, Hassin-Baer S, Cohen OS, Markus A, Tomer R (2014) Asymmetric dopamine loss differentially affects effort to maximize gain or minimize loss. Cortex 51:82-91 Available at: http://dx.doi.org/10.1016/j.cortex.2013.10.004.

Rodriguez P, Aron A, Poldrack R (2006) Ventral-striatal/nucleus-accumbens sensitivity to prediction errors during classification learning. Hum. Brain Mapp. 27:306-13 Available at: http://www.ncbi.nlm.nih.gov/pubmed/16092133 [Accessed January 14, 2015]. 
Schaaf ME Van Der, Schouwenburg MR Van, Geurts DEM, Schellekens AFA, Buitelaar JK, Verkes RJ, Cools R (2014) Establishing the dopamine dependency of human striatal signals during reward and punishment reversal learning. Cereb. Cortex 24:633642

Schultz W (2002) Getting formal with dopamine and reward. Neuron 36:241-263 Available at: http://www.ncbi.nlm.nih.gov/pubmed/12383780 [Accessed December 1, 2014].

Schultz W, Dayan P, Montague PR (1997) A neural substrate of prediction and reward. Science 275:1593-1599 Available at: http://www.sciencemag.org/cgi/doi/10.1126/science.275.5306.1593 [Accessed March 20, 2014].

Shoulson I, Fahn S (1979) Huntington disease: clinical care and evaluation. Neurology 29:1-3 Available at: http://www.ncbi.nlm.nih.gov/pubmed/154626 [Accessed April 13, 2016].

Surmeier DJ, Ding J, Day M, Wang Z, Shen W (2007) D1 and D2 dopamine-receptor modulation of striatal glutamatergic signaling in striatal medium spiny neurons. Trends Neurosci. 30:228-235 Available at: http://linkinghub.elsevier.com/retrieve/pii/S0166223607000690.

Sutton SK, Davidson RJ (1997) Prefrontal Brain Asymmetry: A Biological Substrate of the Behavioral Approach and Inhibition Systems. Psychol. Sci. 8:204-210 Available at: http://pss.sagepub.com/lookup/doi/10.1111/j.1467-9280.1997.tb00413.x.

Tobler PN, Dickinson A, Schultz W (2003) Coding of predicted reward omission by dopamine neurons in a conditioned inhibition paradigm. J. Neurosci. 23:10402-10410

Tomer R, Slagter HA, Christian BT, Fox AS, King CR, Murali D, Gluck MA, Davidson RJ (2014) Love to Win or Hate to Lose? Asymmetry of Dopamine D2 Receptor Binding Predicts Sensitivity to Reward versus Punishment. J. Cogn. Neurosci. 26:1039-1048 Available at: http://www.mitpressjournals.org/doi/abs/10.1162/jocn_a_00544.

Vonsattel JP, Myers RH, Stevens TJ, Ferrante RJ, Bird ED, Richardson Jr. EP (1985) Neuropathological classification of Huntington's disease. J Neuropathol Exp Neurol 44:559-577 Available at: http://www.ncbi.nlm.nih.gov/pubmed/2932539.

Wager TD, Phan KL, Liberzon I, Taylor SF (2003) Valence, gender, and lateralization of functional brain anatomy in emotion: A meta-analysis of findings from neuroimaging. Neuroimage 19:513-531

Weeks RA, Piccini P, Harding AE, Brooks DJ (1996) Striatal D1 and D2 dopamine receptor loss in asymptomatic mutation carriers of Huntington's disease. Ann. Neurol. 40:49-54 Available at: http://www.ncbi.nlm.nih.gov/pubmed/8687191 [Accessed February 15, 2016].

Wilkinson L, Tai YF, Lin CS, Lagnado DA, Brooks DJ, Piccini P, Jahanshahi M (2014) 
Probabilistic classification learning with corrective feedback is associated with in vivo striatal dopamine release in the ventral striatum, while learning without feedback is not. Hum. Brain Mapp. 35:5106-15 Available at:

http://www.ncbi.nlm.nih.gov/pubmed/24777947 [Accessed September 20, 2014].

Zielonka D, Marinus J, Roos R a C, Michele G De, Donato S Di, Putter H, Marcinkowski J, Squitieri F, Bentivoglio AR, Landwehrmeyer GB (2013) The influence of gender on phenotype and disease progression in patients with Huntington's disease. Parkinsonism Relat. Disord. 19:192-7 Available at: http://www.ncbi.nlm.nih.gov/pubmed/23102616. 
Table 1: Model comparison between the stepwise modeling approach with two learning rates (stepwise, 2 LR) and two alternatives: a model with only one learning rate and stepwise fitting (stepwise, $1 \mathrm{LR}$ ) and a model with two learning rates and simultaneous fitting (standard QL).

\begin{tabular}{|c|c|c|c|c|}
\hline & & stepwise, 2 LR & stepwise, 1 LR & standard QL \\
\hline \multirow{6}{*}{$\begin{array}{l}\text { All } \\
\text { subjects } \\
(n=63)\end{array}$} & pseudo-r² & 0.37 & 0.37 & 0.38 \\
\hline & $\mathrm{BIC}$ & 11352 & 11261 & 11241 \\
\hline & $\Delta \mathrm{BIC}$ & 1.76 & 0.32 & - \\
\hline & model frequencies & 0.27 & 0.26 & 0.46 \\
\hline & $\begin{array}{l}\text { exceedance } \\
\text { probabilities }\end{array}$ & 0.03 & 0.02 & 0.95 \\
\hline & regression-model & $\begin{array}{l}R^{2}=0.65 \\
p<0.001\end{array}$ & $\begin{array}{l}R^{2}=0.14 \\
p=0.01\end{array}$ & $\begin{aligned} R^{2} & =0.05 \\
p & =0.4\end{aligned}$ \\
\hline
\end{tabular}

\begin{tabular}{|c|c|c|c|c|}
\hline \multirow[t]{6}{*}{ PET $(n=7)$} & pseudo- $r^{2}$ & 0.25 & 0.25 & 0.23 \\
\hline & $\mathrm{BIC}$ & 1484 & 1485 & 1535 \\
\hline & $\Delta \mathrm{BIC}$ & - & 0.14 & 7.29 \\
\hline & model frequencies & 0.45 & 0.44 & 0.11 \\
\hline & $\begin{array}{l}\text { exceedance } \\
\text { probabilities (\%) }\end{array}$ & 0.5 & 0.48 & 0.02 \\
\hline & regression-model & $\begin{array}{l}R^{2}=.96 \\
p=.01\end{array}$ & $\begin{array}{l}R^{2}=.97 \\
p=.001\end{array}$ & $\begin{array}{l}R^{2}=.96 \\
p=.02\end{array}$ \\
\hline \multirow[t]{6}{*}{ PD $(n=22)$} & pseudo-r ${ }^{2}$ & 0.23 & 0.29 & 0.21 \\
\hline & $\mathrm{BIC}$ & 4677 & 4460 & 4953 \\
\hline & $\Delta \mathrm{BIC}$ & 9.86 & - & 22.41 \\
\hline & model frequencies & 0.24 & 0.51 & 0.25 \\
\hline & $\begin{array}{l}\text { exceedance } \\
\text { probabilities (\%) }\end{array}$ & 0.05 & 0.9 & 0.05 \\
\hline & regression-model & $\begin{array}{c}R^{2}=.91 \\
p=1.17^{\star} 10^{-9}\end{array}$ & $\begin{array}{l}R^{2}=.05 \\
p=.63\end{array}$ & $\begin{array}{l}R^{2}=.11 \\
p=.53\end{array}$ \\
\hline \multirow[t]{6}{*}{ HD $(n=34)$} & pseudo- $r^{2}$ & 0.47 & 0.46 & 0.51 \\
\hline & $\mathrm{BIC}$ & 5192 & 5315 & 4752 \\
\hline & $\Delta \mathrm{BIC}$ & 7.02 & 13.62 & - \\
\hline & model frequencies & 0.29 & 0.03 & 0.68 \\
\hline & $\begin{array}{l}\text { exceedance } \\
\text { probabilities (\%) }\end{array}$ & 0.01 & 0 & 0.99 \\
\hline & regression-model & $\begin{array}{l}R^{2}=.29 \\
p=.02\end{array}$ & $\begin{array}{l}R^{2}=.07 \\
p=.33\end{array}$ & $\begin{array}{l}R^{2}=.04 \\
p=.76\end{array}$ \\
\hline
\end{tabular}

N.B. BIC = Bayesian Information Criterion. Values in bold indicate significant variance explanation. All three tested models showed comparable model fit according to pseudo- ${ }^{2}$ and BIC values. While standard QL shows the best fit according to estimated probabilities and model frequencies across all subjects, $\triangle B I C$ indicate no strong evidence against the other two models. Importantly, despite comparable model fit, only the stepwise model with two learning rates was able to explain significant variance in participants' WPT performance in all three studies according to regression analyses. LR = Learning rate. 


\section{Figure 1}
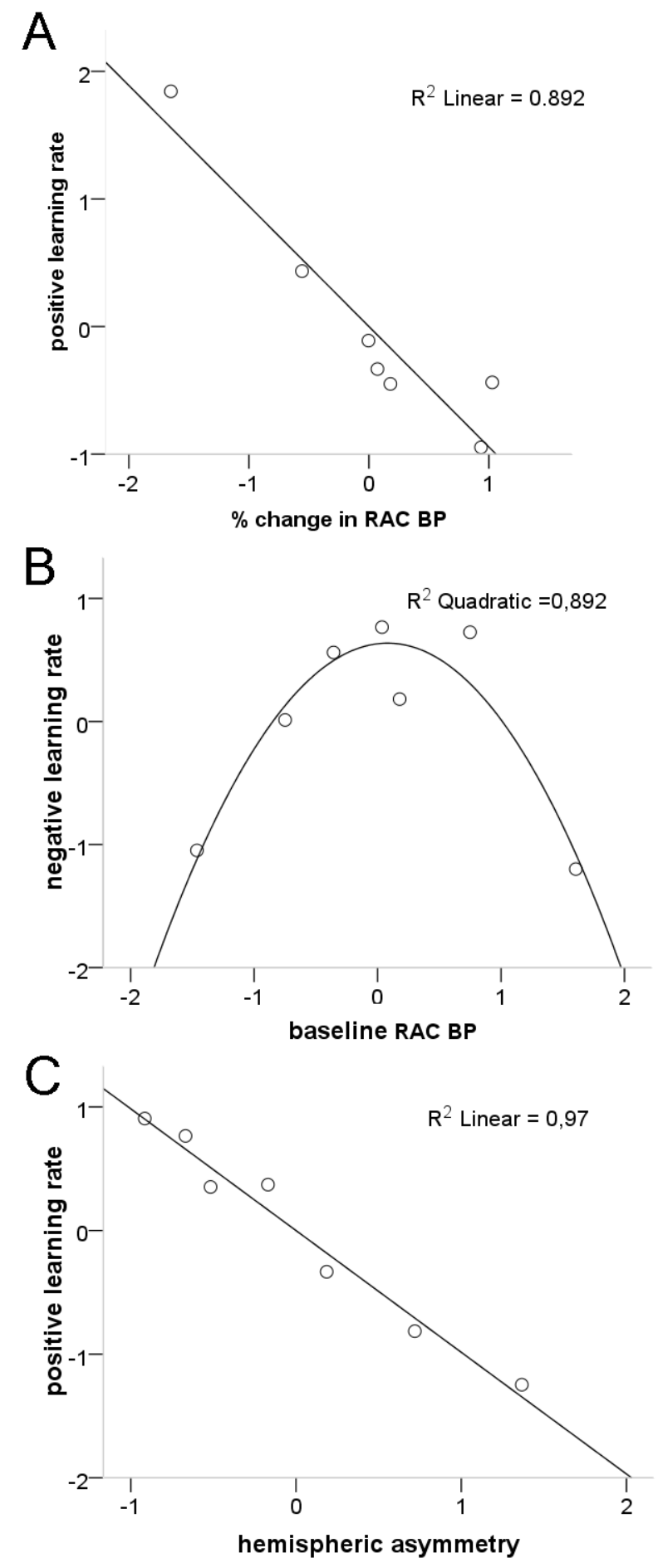

Figure 1 Association between phasic and tonic dopaminergic signaling and learning on the Weather Prediction Task. (A) Dopamine release, as measured by the change in [11C]raclopride binding potential between WPT control and feedback sessions, is positively associated with the ability to learn from positive prediction errors (PEs) in healthy subjects. (B) Dopaminergic tone, as estimated by baseline [11C]raclopride binding potential, is associated with learning from negative PEs in an inverted u-shaped 
manner. (C) Hemispheric asymmetry between left and right ventral striatum in dopaminergic tone is negatively associated with learning from positive PEs.

\section{Figure 2}

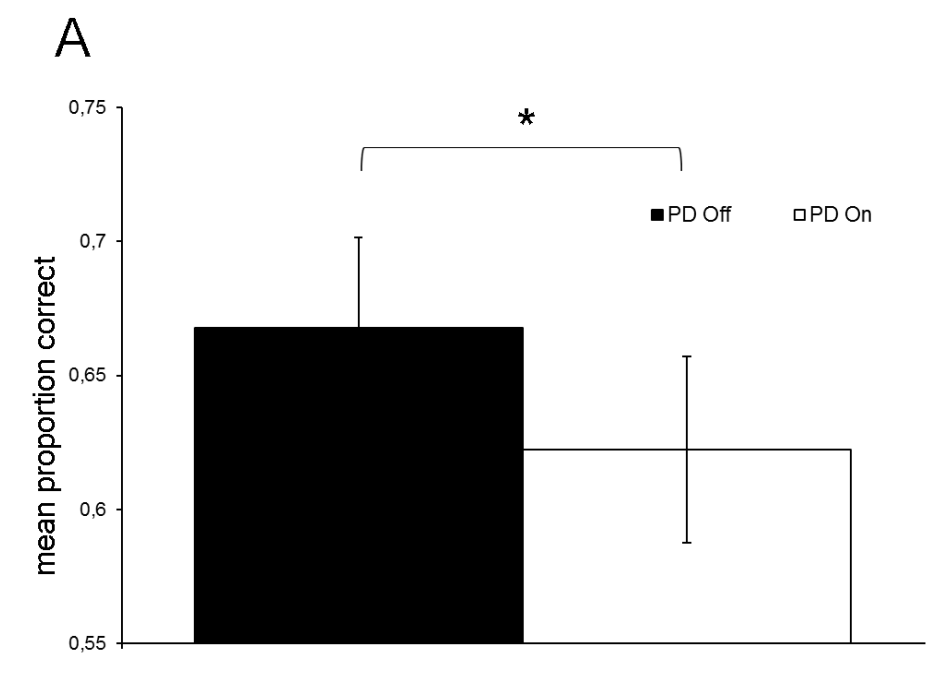

B

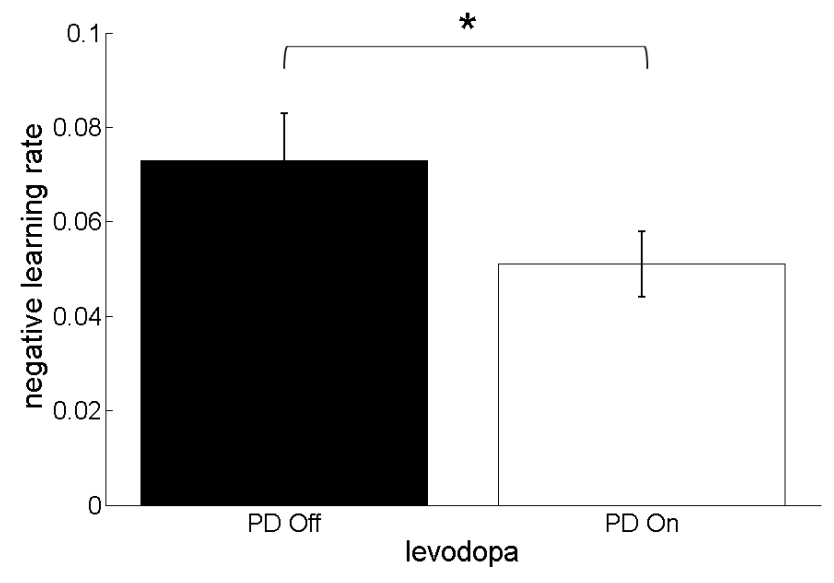

Figure 2 Behavioural differences between off and on dopaminergic medication in patients with Parkinson's disease on the Weather Prediction Task. (A) Mean proportion correct responses on the Weather Prediction Task for Parkinson patients off and on dopaminergic medication. (B) Parkinson patients on dopaminergic medication are impaired in learning from negative prediction errors on the Weather Prediction Task compared to off medication. Asterisk indicates $p<.05$. 


\section{Figure 3}

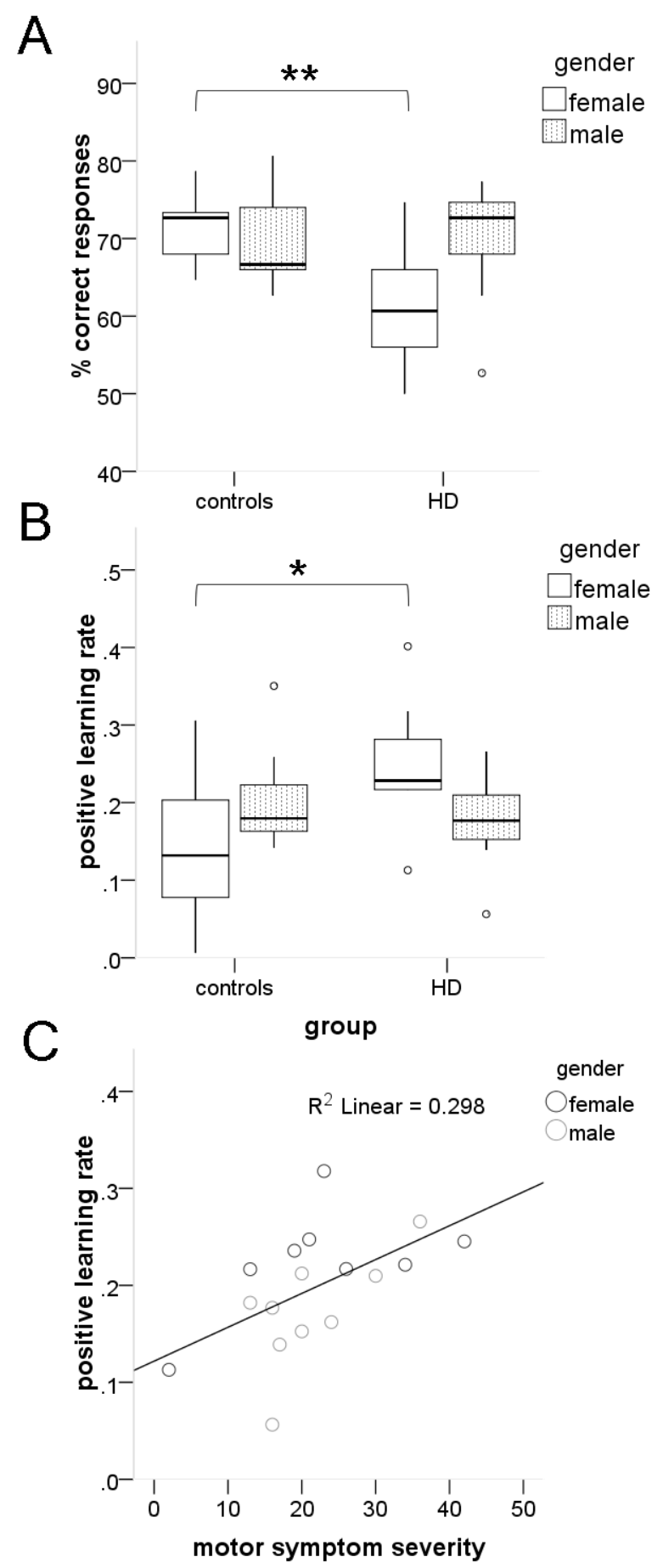

Figure 3 Gender-specific behavioral impairment in patients with Huntington's disease on the Weather Prediction Task. (A) Mean proportion correct responses on the Weather Prediction Task for healthy control subjects and early Huntington Disease (HD) patients split by gender. (B) Interaction between group (control/HD) and gender on the propensity to learn from positive prediction errors on the Weather prediction task. (C) Positive learning rate is positively associated with motor symptom severity across both genders in patients with early Huntington's disease. 